\title{
SD Simulation Research on the Green Low-Carbon Development of Coal Enterprises
}

\author{
Yinna Xu $\mathbb{D}^{1},{ }^{1}$ Guohao Zhao, ${ }^{1}$ Baojian Zhang, ${ }^{2}$ and Jiao Jiao ${ }^{1}$ \\ ${ }^{1}$ School of Business and Administration, Shanxi University of Finance and Economics, Taiyuan 030006, China \\ ${ }^{2}$ School of Management Science and Engineering, Shanxi University of Finance and Economics, Taiyuan 030006, China \\ Correspondence should be addressed to Yinna Xu; xuyinna1991@163.com
}

Received 5 January 2021; Accepted 1 June 2021; Published 14 June 2021

Academic Editor: Wei Zhang

Copyright (c) 2021 Yinna Xu et al. This is an open access article distributed under the Creative Commons Attribution License, which permits unrestricted use, distribution, and reproduction in any medium, provided the original work is properly cited.

The green low-carbon development system of enterprises, differing from the traditional linear system, is a nonlinear feedback system with complex causality. Based on self-organization theory, this study clarified the self-organization evolution logic of the green low-carbon development of coal enterprises and constructed a system dynamics model following a system dynamics method. Through a scenario simulation analysis, the impact of the market environment, environmental regulation, and enterprises' innovation level on the green low-carbon development of coal enterprises was revealed. Applicability suggestions based on simulation results were proposed. The results confirmed that the main challenge for coal enterprises is that the coal market environment restricts the promotion of green low-carbon development level of coal enterprises. Improving innovation levels is the most effective way for coal enterprises to address these issues.

\section{Introduction}

Since 1980, the concept of sustainable development was first put forward in the World Conservation Strategy jointly published by the International Union for Conservation of Nature (IUCN), the United Nations Environment Programme (UNEP), and the World Wide Fund for Nature (WWF). The Our Common Future report published by the World Commission on Environment and Development (WCED) in 1987 defines sustainable development as development that meets the needs of the present without compromising the ability of future generations to meet their own needs [1]. So far, how to balance the relationship between the economy, society, environment, and energy has become the focus of attention of all countries. In recent years, extreme weather events such as hot summers, droughts, and floods have frequently occurred worldwide. There is evidently an urgent need to address global climate change. In November 2016, the Paris Agreement on Climate Change came into force, and this agreement demonstrates the belief and determination of all countries to deal with climate change. To cope with climate change, green low- carbon development has become the development trend for all countries in the world [2]. According to the International Energy Agency (IEA)'s global coal market report for 2018-2023, coal still constitutes the core source of fuel in the global energy system, and it still remains the main source of energy in many countries. As a large coal-consuming country, the status of coal as the main source of energy in China is not expected to change in the foreseeable future. Hence, the clean and efficient use of green low-carbon coal development is extremely important, since coal enterprises-as the main bodies of the microeconomy-bear an important responsibility in this area. In recent years, how to better achieve green low-carbon development of coal enterprises in the future has been a key focus of research.

With social development and global environmental change, a series of sustainable development paradigms, such as green economy, green development, circular development, low-carbon economy, and low-carbon development, have been proposed as solutions to address such social and environmental changes. Green development focuses on environmental protection, which is a development model that considers economic development and ecological 
environment protection, contemporary economic prosperity, and future generations' development, and at the core of low-carbon development are energy issues, that is, the pursuit of high resource productivity with less resource consumption and less pollution. At present, China not only needs to continue to address the problem of regional environmental pollution but also needs to deal with the global problem of climate change. Therefore, it is of great academic value and practical significance to put forward the concept of green low-carbon development and to study how green lowcarbon development can be achieved. This study considers green low-carbon development as an organic combination of green development and low-carbon development. We not only pay attention to the protection of the ecological environment but also take into account resource saving, energy efficiency improvement, and emission reduction. At the same time, this study aims to achieve a coordinated development of economic development, environmental protection, and resource utilization. Its essential goal is to provide a means to achieve the coordinated development of economic development, environmental protection, and resource consumption, and green innovation is important in this regard. The system thought of "the whole is greater than the sum of parts" could provide theoretical support and development ideas for research on the green economy [3]. At the same time, the meaning of coupling includes development and coordination, which not only includes the "quantity expansion" part of system evolution development but also the "quality improvement" part of mutual cooperation and harmonious development among systems [4], which provides a way to evaluate green low-carbon development. Thus, this study uses the system analysis method to analyze the green low-carbon development of coal enterprises and introduces the coupling coordination degree to measure the green low-carbon development level of coal enterprises.

The self-organization theory examines how complex systems automatically evolve from disorder to order, from low-level order to high-level order, and provides ideas for clarifying the logic and mechanism of the green low-carbon development of coal enterprises. Meanwhile, the system dynamics model provides a causal description or structureoriented model that aims to reproduce the historical behavior of a real system and explain the structural determinants of this behavior [5]. It has special advantages in dealing with complex dynamic feedback systems with nonlinear interactions. The tools of system dynamics can provide a more complete picture of the economics of the growth of a firm and stronger and more general conclusions about the evolution of self-organizing market structures [6]. On the one hand, the system dynamics method can better reflect the causality and action mechanism in the process of green low-carbon development of coal enterprises. On the other hand, through simulation, we can better analyze the impact of the market environment, environmental regulation, and enterprises' innovation level on the green and lowcarbon development of coal enterprises. The contributions of this study are as follows: (1) the coupling coordination degree model is introduced to measure the green low-carbon development level of enterprises with the coupling coordination degree among enterprise economic, environmental, and energy systems, which supplements the existing literature on evaluating the green low-carbon development level of enterprises. (2) Based on the self-organization theory, this study clarifies the green low-carbon development mechanism of enterprises and influencing factors from a systematic perspective. (3) The simulation results show that improving the innovation level and promoting the intelligent construction of coal mines are the most effective ways to achieve sustainable green low-carbon development of coal enterprises.

The remainder of this paper is organized as follows. The second section, following the self-organization theory, clarifies the self-organization evolution logic and action mechanism of the green low-carbon development of coal enterprises, as the basis of system modeling. In the third section, we use the system dynamics method to build a simulation model of the green low-carbon development system of coal enterprises. In the fourth section, the system model is simulated with relevant coal industry data. Through a scenario simulation analysis, this study reveals the impact of market environment, environmental regulation, and enterprises' innovation level on the green low-carbon development of coal enterprises. Finally, based on the simulation results, suggestions for the green low-carbon development of coal enterprises are proposed.

\section{Theoretical Logic}

The German theoretical physicist Harken first put forward the concept of self-organization. He believed that "if a system is not interfered with by the outside world in the process of acquiring space, time, or functional structure, it is said that the system is self-organized." Here, "not interfered by the outside world" means that the structure or function is not imposed on the system by the outside world, and the outside world acts on the system in a nonspecific manner. Luo proposed that "self-organization refers to the process of things moving towards organization or order through spontaneity [7]." The self-organization theory mainly involves complex system problems [8]. This study holds that the green low-carbon development of coal enterprises refers to a sustainable development method to achieve the coordinated development of environmental performance and economic performance of coal enterprises through technological innovation and other means to improve energy efficiency, reduce energy consumption, and reduce emissions. After the early blind pursuit of economic benefits and extensive mining and operation, coal enterprises have had to abandon the original development mode of "high pollution and high energy consumption" and choose the mode of green low-carbon development to pursue the balanced and coordinated development of economic development and ecological environment. The green low-carbon development system of coal enterprises is a complex system for coal enterprises to enhance their adaptive ability and ensure sustainable development in response to market and environmental changes. In addition, the green low-carbon 
development process of coal enterprises is a self-organization process of their green low-carbon development system. It is a process in which the subsystems (economy, environment, energy, etc.) of the green low-carbon development system interact with each other and cause the entire system to evolve from disorder to order through feedback, interaction, and promotion.

First, the green low-carbon development system of coal enterprises is open. Dissipative structure theory requires that the system should be open. Through the exchange of material, information, and energy with the environment, the system introduces negative entropy flow from the outside to offset an increase in its positive entropy and promotes the system to evolve from disorder to order [9]. The openness of the green low-carbon development system of coal enterprises is reflected in that, in the process of this development, the three subsystems frequently exchange material, information, and energy with the external environment, obtain market environment, ecological environment, and government policy information, introduce advanced technology and talent, and offset the positive entropy flow generated in the system. The openness of the green low-carbon development system of coal enterprises is the basic premise to ensure its development from disorder to order. Only by fully opening and grasping the market environment dynamics can the green low-carbon development system of coal enterprises adapt to the environment and not be eliminated by the market and society [10]. Simultaneously, the openness of the system also provides a boost to the orderly development of the system.

Second, the green low-carbon development of coal enterprises is far from being at an equilibrium. When coal enterprises encounter market environment changes (such as coal price fluctuations, supply, and demand structure changes) or environmental policy changes, environmental protection requirements increase, which inevitably introduce new challenges to the environmental benefits and economic development of coal enterprises. To adapt to environmental changes, maintain development, and pursue benefits, coal enterprises must respond, distance themselves from the initial equilibrium state and reallocate resources among subsystems, improve their level of technological innovation, and seek new collaborative development among subsystems. The self-organization process of the green lowcarbon development system of coal enterprises is a process in which coal enterprises constantly break the existing balance, distance themselves from the balance state, and then seek a new orderly and stable state in response to environmental changes.

Third, there is a nonlinear mechanism between the internal elements of the green low-carbon development system of coal enterprises. The "order parameters" of this development system derive from the three subsystems of economy, environment, and energy, including the economic situation, environmental situation, and energy situation of coal enterprises. These order parameters compete, cooperate, coordinate, and feed back to each other [11], which promotes the internal subsystems of the green low-carbon development system of coal enterprises to connect and restrict each other and realize the coupling and coordinated development among subsystems through resource allocation and integration. The interaction between order parameters is nonlinear and is represented by nonlinear equations in the process of system evolution.

Finally, fluctuation is the driving force for the evolution of the green low-carbon development of coal enterprises. On the one hand, the fluctuation in the evolution of this development system derives from the influence of external environmental elements, such as changes in the coal market environment, the coal price, the supply and demand structure, the market science and technology level, government policy changes, and ecological environment changes. These factors will continue to affect the interaction between the various systems of coal enterprises, changing the resource allocation among the subsystems of the coal enterprise, which makes the green low-carbon development system of coal enterprises rise and fall; on the other hand, the fluctuation in the evolution of this development system comes from the influence of the internal innovation level. The coupling and coordinative evolution among the economic, environmental, and energy subsystems of the green low-carbon development internal system of coal enterprises is affected by a system's innovation level. A change in the innovation level affects the fluctuation of elements of each subsystem and constantly affects the interaction among subsystems, which leads to a change in the collaborative feedback among subsystems. This change also leads to the green low-carbon development internal system of coal enterprises fluctuating, continuously coupling and coordinating evolution, and enhancing the degree of order.

In summary, this study proposes a self-organization system model of green low-carbon development of coal enterprises, as shown in Figure 1.

\section{Method, Model, and Data}

3.1. System Boundary Analysis. The openness of the green low-carbon development system of coal enterprises ensures that coal enterprises are able to exchange different materials, energy, and information with the external environment, interact with the external environment, and form a certain system boundary. In this study, the system is divided into three subsystems: economic, environment, and energy subsystems. The coupling and coordinated development of the three subsystems is the core of green low-carbon development. Among these, the economic subsystem mainly considers the industrial output value and the number of employees of coal enterprises, the environmental subsystem considers $\mathrm{SO}_{2}$ emissions and $\mathrm{CO}_{2}$ emissions per unit output value, and the energy subsystem considers the total energy consumption and energy consumption per unit output value. As the main external factors, government environmental regulation and market environment change affect the role of internal systems. The strengthening of government environmental regulation increases the pressure on the internal environment of enterprises, and enterprises increase the allocation of resources in the environment. At the same 


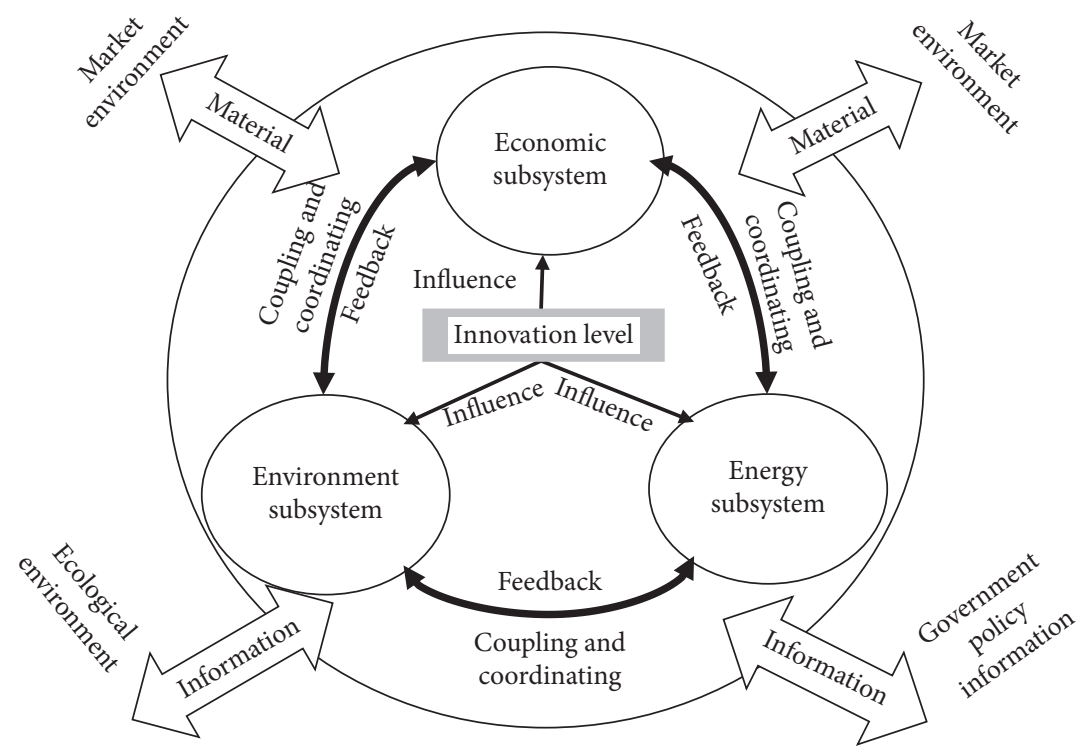

FIGURE 1: Self-organization system model for coal enterprises' green low-carbon development.

time, internal feedback will stimulate enterprises to improve their innovation ability and ensure the coordinated development of the economy and the environment [12]. Changes in the market environment have an impact on the economic development of enterprises. To ensure that enterprises will not be eliminated by the market, improve their core competitiveness, and achieve sustainable development, the internal system must make corresponding responses, the allocation of resource elements among systems should be adjusted, their innovation ability enhanced, and the overall coordination ability of the internal system improved. At the same time, it can be seen that the innovation level within the system is the main influencing factor in this area, which affects the change in the order parameters of the economic, environmental, energy subsystems and, subsequently, the interaction among subsystems.

3.2. Logical Framework of the SD. Model system dynamics (SD) is a methodology and mathematical modeling technique used to frame, understand, and discuss dynamic behaviors and issues of complex systems by setting variables with positive and negative feedback and is integrated by management science and computer simulation technology. Based on the above analysis, the system dynamics causality logical diagram of the green low-carbon development of coal enterprises is constructed, as shown in Figure 2.
3.3. System Stock Flow Chart and Main Equations. According to the causality diagram of the green low-carbon development system of coal enterprises, a stock flow diagram of this system is drawn (as shown in Figure 3). The dynamic stock flow diagram of the system is the basis for the quantitative analysis of dynamic evolution. It is a graphical representation that further distinguishes the properties of variables and uses more intuitive symbols to represent the logical relationship of elements between systems [13]. Considering the quantifiability of variables and the availability and reality of data, this study adjusts and simplifies the causality diagram [14] and generates a stock flow diagram that includes 1 state variable, 1 rate variable, 6 constants, and 27 auxiliary variables. Among these, coupling coordination degree is an important observation variable, which shows the coupling coordination level of the system, that is, the green low-carbon development level of coal enterprises. Market impact factor, enterprise $\mathrm{R} \& \mathrm{D}$ investment intensity, and environmental regulation intensity are the important adjustment parameters of the system. By adjusting these parameters, the scenario observation system is set, and the auxiliary variables of industrial output value, number of employees, $\mathrm{CO}_{2}$ emissions per unit output value, $\mathrm{SO}_{2}$ emissions, total energy consumption, and energy consumption per unit output value of coal enterprises are the representative indexes of the economic, environmental, and energy conditions. The main equations in this study are as follows: 
Cumulative number of patent applications = INTEG (Annual increase of patent application, 375),

Industrial output value of coal enterprises $=$ Market impact factor $*(394226 *$ Coal price +11898.5

* Cumulative number of patent applications $-1.115 e+08), \quad R^{2}=0.879$

Environmental protection investment $=$ Investment intensity of environmental protection

* $(1.75 e-05 *$ Industrial output value of coal enterprises $-0.038 *$ Gap delay +7883.38$)$,

R\&D investment $=(0.005 *$ Industrial output value of coal enterprises +33.233$)$

* Enterprise R\&D investment intensity $R^{2}=0.9239$,

$\mathrm{SO}_{2}$ emissions $=-11.293 *$ Environmental protection investment -0.461

* Cumulative number of patent applications +243769 ,

$\mathrm{SO}_{2}$ emissions gap $=-11.293 *$ Environmental protection investment -0.461

* Cumulative number of patent applications +243769 ,

Gap delay = DELAY FIXED ( $\mathrm{SO}_{2}$ emissions gap, 1, 25000),

$\mathrm{CO}_{2}$ emissions $=$ Coal consumption $* \mathrm{CO}_{2}$ emission coefficient of coal + Electricity consumption

* $\mathrm{CO}_{2}$ emission coefficient of electricity,

$\mathrm{CO}_{2}$ emissions per unit output value $=\frac{\mathrm{CO}_{2} \text { emissions }}{\text { Industrial output value of coal enterprises }}$,

Total energy consumption $=$ Coal consumption + Electricity consumption,

Energy consumption per unit output value $=\frac{\text { Total energy consumption }}{\text { Industrial output value of coal enterprises }}$,

Coal price $=$ with lookup $([(2006,400)-(2020,900)],(2006,426.73),(2007,465.59),(2008,729)$,

$(2009,600.2)(2010,745.2),(2011,822),(2012,706.3),(2013,591)$,

((2014, 516.7) (2015, 516.73), (2016, 473.9), (2017, 639.5), (2018, 639.53), (2019, 593), (2020, 570),

Coupling degree $=\frac{27 * \text { Energy situation } * \text { Economic situation } * \text { Environmental situation }}{(\text { Environmental situation }+ \text { Economic situation }+ \text { Energy situation })^{3}}$,

Coordination degree $=\frac{(\text { Environmental situation }+ \text { Economic situation }+ \text { Energy situation })}{3}$,

Coupling coordination degree $=(\text { Coordination degree } * \text { Coupling degree })^{1 / 2}$,

Standardization of variable $x_{i}: x_{i}^{\prime}= \begin{cases}\frac{\max \left(x_{i}\right)-x_{i}}{\max \left(x_{i}\right)-\min \left(x_{i}\right)}, & x_{i} \text { has negative effect, } \\ \frac{x_{i}-\min \left(x_{i}\right)}{\max \left(x_{i}\right)-\min \left(x_{i}\right)}, & x_{i} \text { has positive effect, }\end{cases}$

Economic situation $=0.5 *$ Standardization of the number of employees +0.5

* Standardization of industry output value of coal,

Environmental situation $=0.5 *$ Standardization $\mathrm{SO}_{2}$ emission +0.5

* Standardization of $\mathrm{CO}_{2}$ emissions per unit output value, 


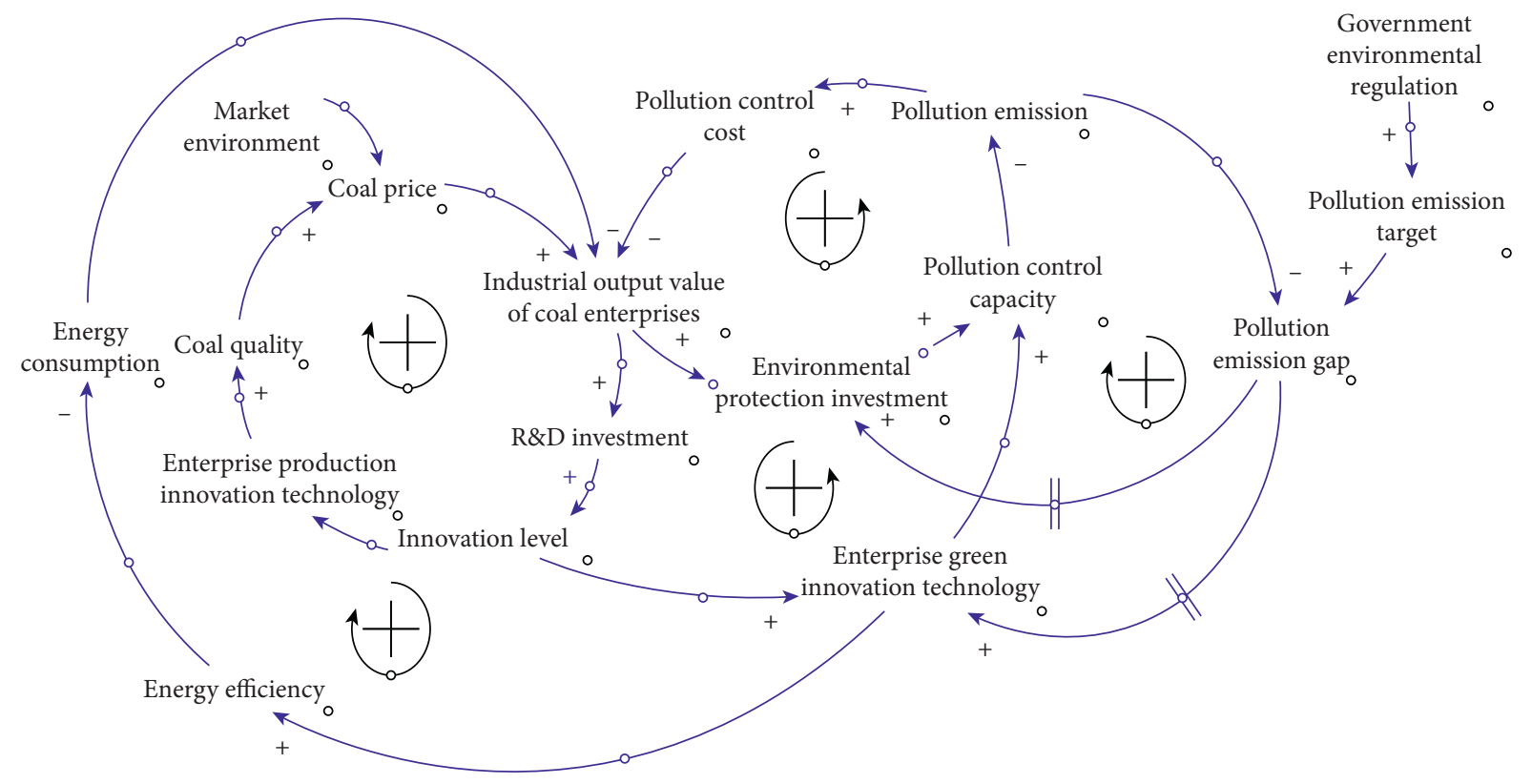

FIgURE 2: Logical framework of the SD model.

Energy situation $=0.5 *$ Standardization of total energy consumption +0.5

* Standardization of energy consumption per unit output value,

$\mathrm{CO}_{2}$ emission coefficient of electricity $=1.3203$,

$\mathrm{CO}_{2}$ emission coefficient of coal $=1.9003$.

3.4. Data Sources. The data used in this study has been sourced principally from statistical yearbooks such as the China Statistical Yearbook, the China Industrial Statistical Yearbook, the China Environmental Statistical Yearbook, the China Science and Technology Statistical Yearbook, and the China Energy Statistical Yearbook, among others. This study also refers to a number of government planning documents and reports. For example, the emission targets of $\mathrm{SO}_{2}$ in our study are sourced from the "11th Five-Year Plan," the "12th Five-Year Plan," and the "13th Five-Year Plan." Meanwhile, the $\mathrm{CO}_{2}$ emission coefficients of coal and electricity are sourced from the guidelines of the Intergovernmental Panel on Climate Change. The relationship and equation of the variables in our model have been mainly determined using a regression analysis and table function. The trend extrapolation method has been used to supplement the missing values. The application of the table function effectively deals with nonlinear relationships. The parameters in the model are set according to the principle of real data and reasonable inference. The initial value is set based on actual data from 2006. To simplify the model parameters, the model takes the variables that are used to adjust and control the scenario setting as constants, such as market influence factor, enterprise $R \& D$ investment intensity, and environmental regulation intensity. At the same time, to reduce the error between the simulation results and historical data as much as possible, some parameters are adjusted in the process of model calibration.

\section{Model Checking}

System dynamics modeling seeks to solve problems in analyses through a system analysis and scenario simulation. The effectiveness of a system determines the applicability of a model [15]. Therefore, to ensure the correctness, rationality, and effectiveness of the model, it is necessary to verify the validity of the model before it is applied in a simulation. The commonly used methods of system dynamics model testing include applicability tests, consistency analyses, historical value tests [16], function tests, structural tests [17], extreme value tests [18], and sensitivity tests [19]. Historical value and sensitivity tests are commonly used test methods. In this study, the validity of the model is tested using a historical value test and a sensitivity test.

4.1. Historical Value Testing. $\mathrm{SO}_{2}$ emission is an important indicator of the environmental status of coal enterprises. In this study, comparing the real value with the simulated value from 2006 to 2015, SO $\mathrm{SO}_{2}$ emission can be used to test the robustness of the model. The results from our related analysis are shown in Table 1, which shows that the error rate 


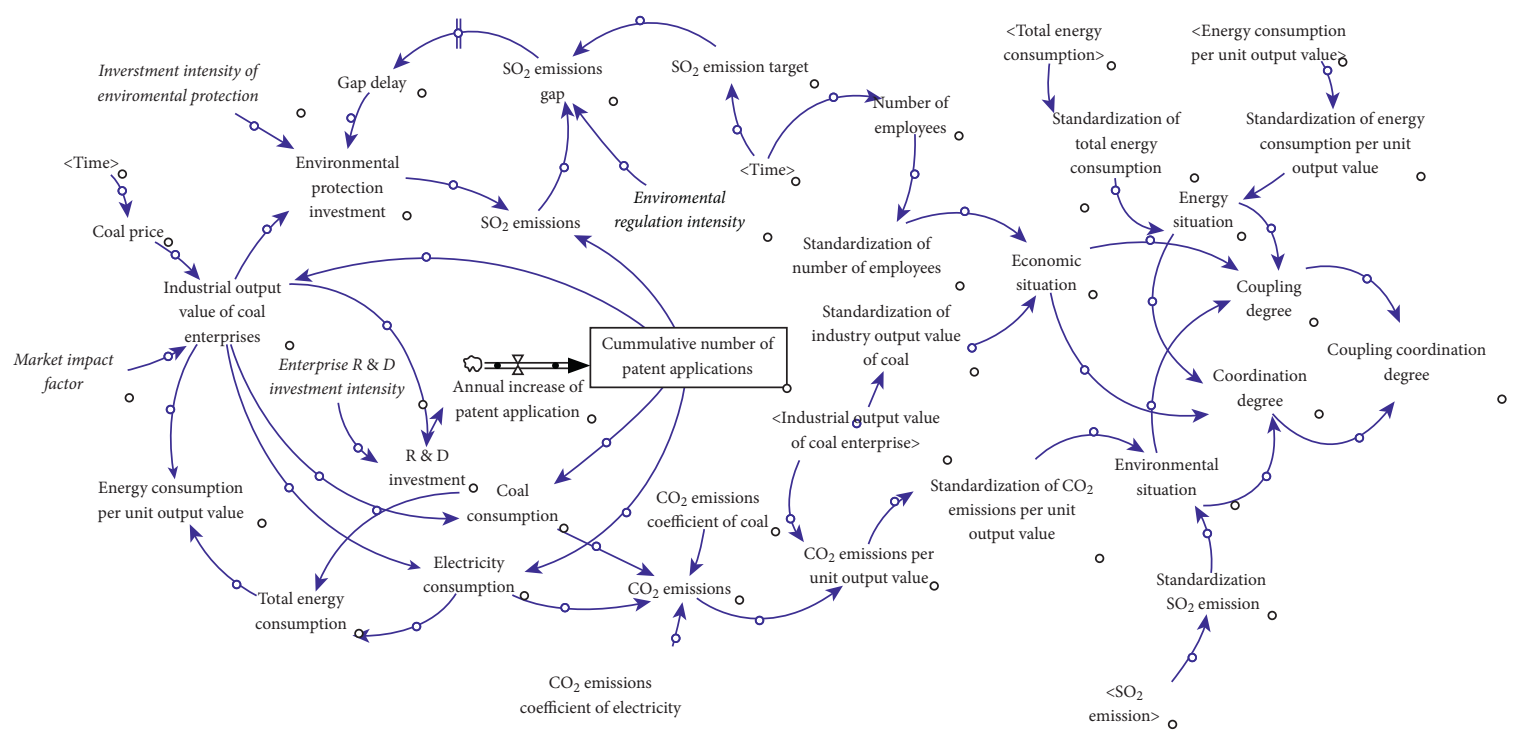

FIGURE 3: Stock flow chart of the green low-carbon development system of coal enterprises.

between the simulation value and the real value is within $10 \%$, and the average error is $1.98 \%$, which is within the acceptable error range. Therefore, the model established in this study has passed the test of the historical value and can reflect the real situation of the green low-carbon development system of coal enterprises.

4.2. Sensitivity Testing. Sensitivity testing is used to test the sensitivity of a system to parameter adjustment by changing the values of some parameters in the model to observe the changes in the operation results of the model. According to the green low-carbon development system model of coal enterprises constructed in this study, combined with the model construction logic mentioned above, enterprises' innovation level (cumulative number of patent applications) has an important impact on the economy, environment, and energy system, and the enterprise R\&D (research and development) investment intensity has a direct impact on the innovation level. Therefore, this study selects enterprise $\mathrm{R} \& \mathrm{D}$ investment intensity as a test variable to evaluate the sensitivity of $\mathrm{SO}_{2}$ emission, industrial output value of coal enterprises, $\mathrm{CO}_{2}$ emission per unit output value, and energy consumption per unit output value on the change in the R\&D investment intensity of enterprises. The R\&D investment intensity parameter is adjusted from 1 to 1.2 and then reduced to 0.8 . The simulation results are shown in Figure 4. It can be seen that when the $R \& D$ investment intensity increases (reduces), the innovation level improves (reduced), and the trend of $\mathrm{SO}_{2}$ emission, industrial output value of coal enterprises, energy consumption per unit output value, and $\mathrm{CO}_{2}$ emission per unit output value over time is consistent with that under the original scenario, but the range of decrease of $\mathrm{SO}_{2}$ emission, energy consumption per unit output value, and $\mathrm{CO}_{2}$ emission per unit output value becomes larger (smaller), and the range of increase of the industrial output value of coal enterprises also becomes larger (smaller). Therefore, the model conforms to reality and theoretical logic and has no strict requirements for parameters. It has passed the sensitivity test and is suitable for application as our actual model.

\section{Results and Analysis}

5.1. Scenario Design. A scenario analysis can describe the development direction of research objects through different scenarios [20], which has become a common method for providing evidence and analyzing development planning investment, especially with regards to low-carbon development and different green economy strategies [21]. The purpose of this study is to analyze the impact of internal and external factors on the green low-carbon development of coal enterprises and the path of green low-carbon development of these enterprises by building a system model of this development. Based on the theoretical analysis of the previous model, mainly considering the impact of the market environment, government environmental regulation, and enterprise innovation level, six scenarios (as shown in Table 2) are formed by adjusting the setting of the three parameters of market influence factor, environmental regulation intensity, and enterprise R\&D investment intensity. By observing the corresponding changes in an enterprise's economic situation, environmental situation, energy situation, and coupling coordination degree under different situations, the influence of different influencing factors can be analyzed to provide a decision-making reference for the future green and low-carbon development path of coal enterprises.

In our analysis, the "original scenario" refers to a parameter setting based on the actual real-world situation, which reflects the trend of the green low-carbon development of coal enterprises based on historical situations. Scenarios 1 to 3 adjust a single parameter to reflect the impact of the market environment, government environmental regulation, and enterprise innovation level on the green low-carbon development of coal enterprises. 
TABLE 1: Historical value testing.

\begin{tabular}{lcccccccccc}
\hline Year & 2006 & 2007 & 2008 & 2009 & 2010 & 2011 & 2012 & 2013 & 2014 & 2015 \\
\hline Real value & 145000 & 175300 & 148700 & 149861 & 160255 & 129254 & 124866 & 126231 & 114320 & 105000 \\
Simulated value & 153205 & 161213 & 134311 & 150901 & 148430 & 126336 & 117049 & 124041 & 121678 & 107923 \\
Error rate & -0.0566 & 0.0804 & 0.0968 & -0.0069 & 0.0739 & 0.0226 & 0.0626 & 0.0173 & -0.0644 & -0.0278 \\
Average error & & & & \multicolumn{2}{c}{0.0198} & \\
\hline
\end{tabular}

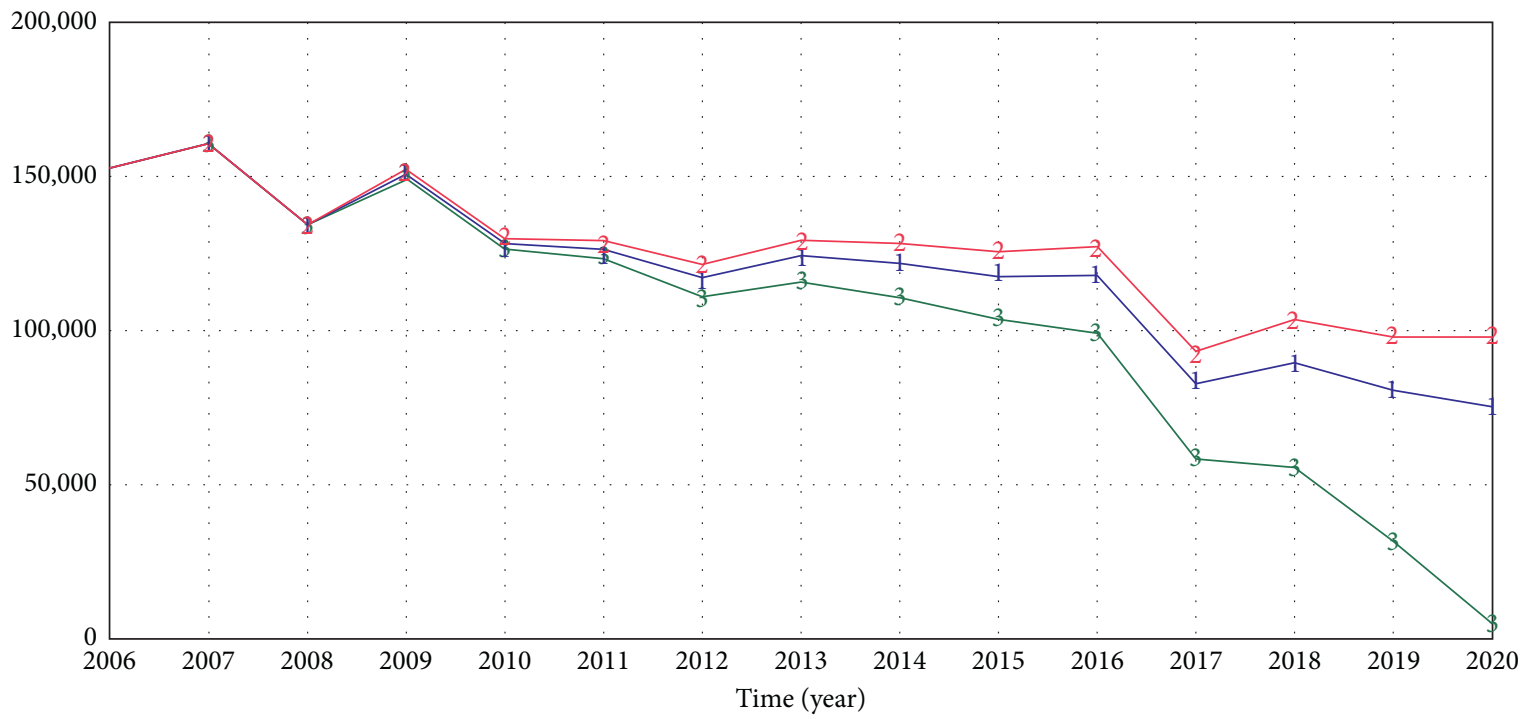

$1-\mathrm{SO}_{2}$ emissions: sensitivity test-original

$2-\mathrm{SO}_{2}$ emissions: sensitivity test-reduced $\mathrm{R} \& \mathrm{D}$ investment intensity

3- $\mathrm{SO}_{2}$ emissions: sensitivity test-increased $\mathrm{R} \& \mathrm{D}$ investment intensity

(a)

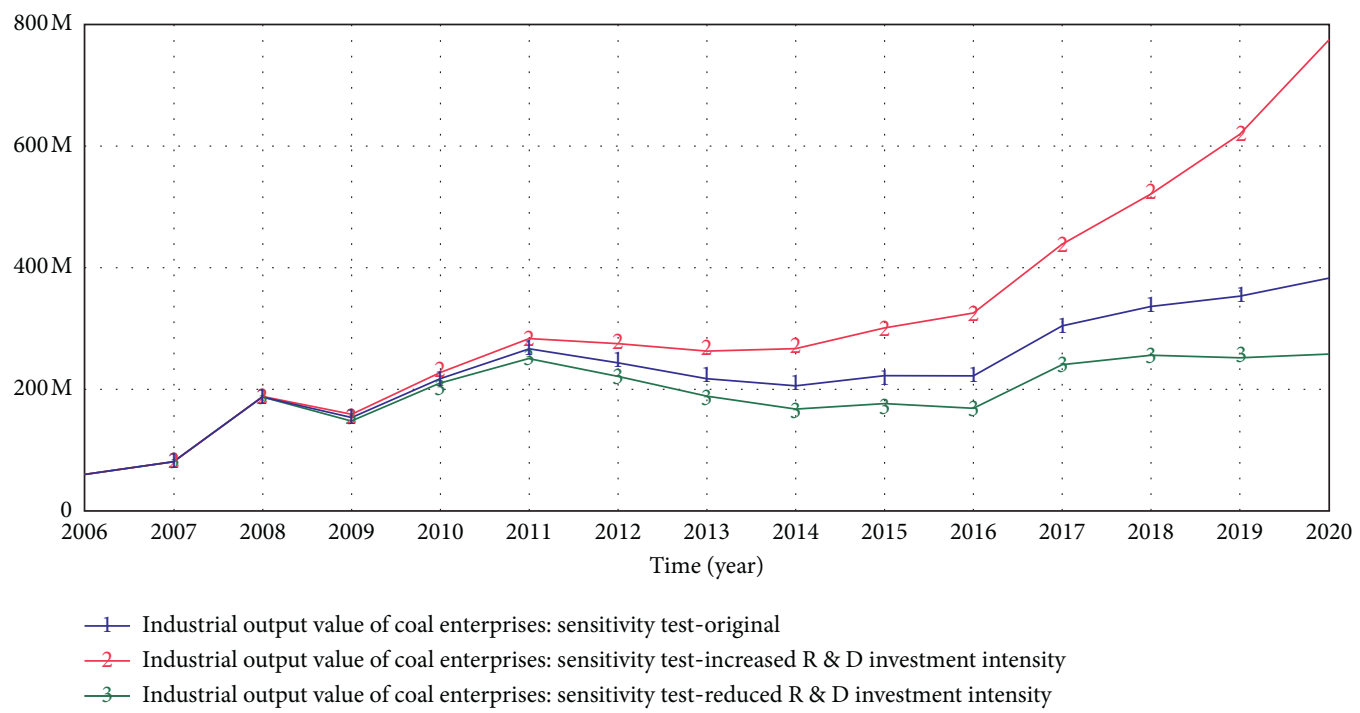

(b)

FIgURE 4: Continued. 


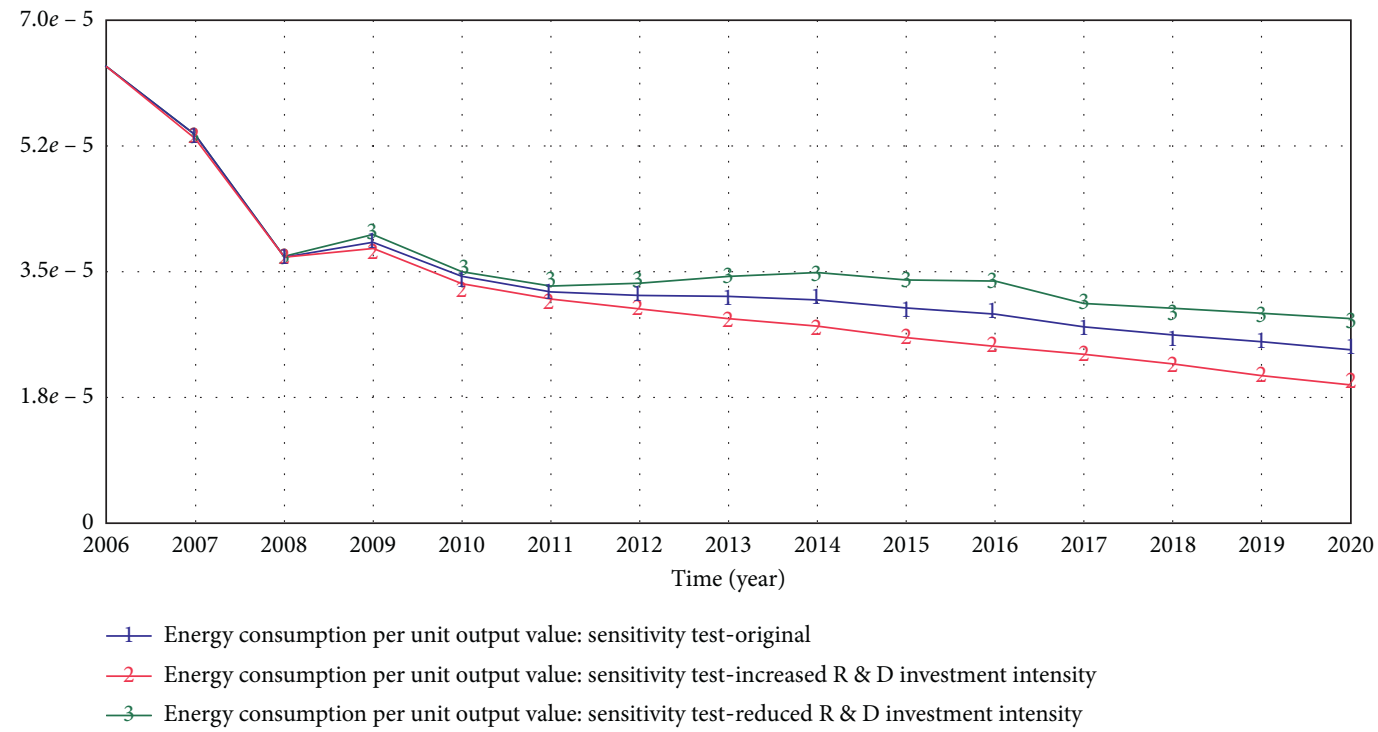

(c)

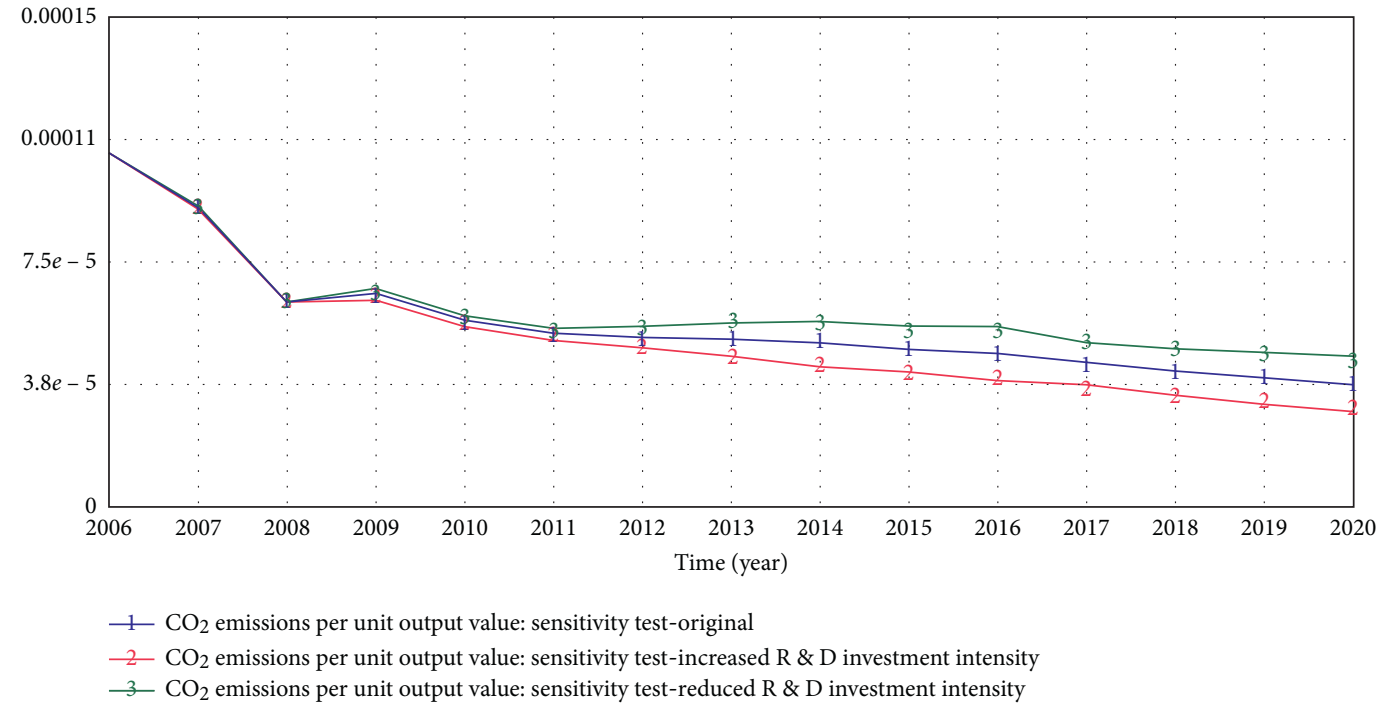

(d)

Figure 4: Parameter sensitivity test results. (a) $\mathrm{CO}_{2}$ emission. (b) Industrial output value of coal enterprises. (c) Energy consumption per unit output value. (d) $\mathrm{CO}_{2}$ emission per unit output value.

TABLE 2: Scenario analysis parameter setting table.

\begin{tabular}{|c|c|c|c|c|c|c|c|}
\hline Parameter & Original scenario & Scenario 1 & Scenario 2 & Scenario 3 & Scenario 4 & Scenario 5 & Scenario 6 \\
\hline Marke & 1 & 1.1 & 1 & 1 & 1.1 & 1 & 0.9 \\
\hline Environmental regulation intensity & 1 & 1 & 1.2 & 1 & 1.2 & 1.2 & 1 \\
\hline Enterprise R\&D investment intensity & 1 & 1 & 1 & 1.2 & 1 & 1.2 & 1.4 \\
\hline
\end{tabular}

Scenarios 4 to 6 adjust multiple parameters simultaneously to reflect the comprehensive impact of the market environment, government environmental regulation, and enterprise innovation level on the green low-carbon development of coal enterprises. Scenario 4 discusses whether strengthening environmental regulations would benefit the green low-carbon development of coal enterprises if the market environment is slightly warmer.
Scenario 5 discusses whether the market environment remaining unchanged as well as environmental regulations being strengthened and the level of enterprises' innovation being improved will produce better results. Scenario 6 discusses whether adjusting the intensity of R\&D investment can improve the green low-carbon development of coal enterprises if the market environment further deteriorates. 


\subsection{Scenario Simulation Results and Analysis}

5.2.1. Original Scenario Analysis. Figure 5 shows the trend in changes regarding the green low-carbon development of coal enterprises under the original scenario, that is, the trend in changes of the coupling coordination degree, economic situation, energy situation, and environmental situation. The economic situation of coal enterprises shows a trend of growth first and then decline. Before 2012, it grew each year and then declined rapidly from 2012 to 2016. After 2016, it still showed a downward trend, but the speed of decline slowed down. The environmental situation of coal enterprises is improving and essentially shows a trend of increasing each year. The energy situation experienced a shortterm rapid growth from 2006 to 2008, reached a good level, and then showed a steady development trend. The green low-carbon development level of coal enterprises (coupling coordination degree) experienced a rapid improvement stage before 2013, and then began to decline after 2013. This is mainly affected by the environment of China's coal industry. Before 2013, China's coal industry experienced a "golden decade" in which the demand for coal surged, coal prices soared, and coal enterprises made huge profits. However, due to the slowdown in the demand for coal and the impact of imported coal, China's coal market stagnated overall after 2013, and the economy of coal enterprises has been seriously damaged. After the 18th National Congress of the Communist Party of China, the coal industry carried out structural reforms on the supply side, solved the excess capacity, and merged and reorganized large coal enterprises. As a result, the coal market gradually changed from oversupply to a supply-demand balance. The coal market gradually recovered, and the economic benefits of enterprises improved. On the contrary, environmental constraints have been strengthened further, the environmental situation of coal enterprises is steadily improving, and energy consumption is stable. Hence, while the green lowcarbon development level of coal enterprises has entered a declining stage since 2013, it has not decreased significantly. The change in the economic benefits of coal enterprises caused by the change of the market environment and the intensity of government environmental regulations will have an impact on the green low-carbon development level of coal enterprises. At present, how to further activate the coal industry and promote its high-quality development as well as how to seek a self-development mode in a dynamic environment remain as top priorities.

\subsubsection{Scenario Analysis under Single Factor Influence.} Figure 6 shows a comparison of the green low-carbon development levels of coal enterprises under the original scenario and Scenarios 1, 2, and 3. At the beginning of 2016, the Chinese State Council issued the "Opinions on Resolving Overcapacity and Realizing the Development of the Coal Industry," which clarified the direction of reform for the coal industry. Following the implementation of coal capacity reduction reforms, the coal market slowly warmed up. Scenario 1 raised the market impact factor to 1.1 , aiming to simulate change in the green low-carbon development level of coal enterprises under the situation that the coal market turned better, coal prices rose, and the economic benefits of coal enterprises improved; to cope with climate change, environmental pollution and greenhouse gas emissions are still long-term tasks for China. In the second scenario, the intensity of environmental regulation increased to 1.2 , which is intended to simulate change in the green low-carbon development level of coal enterprises under the situation of further strengthening environmental regulation, and as an important factor in the system, the change in enterprises' innovation level will have an important impact on the three subsystems. Scenario 3 increases the enterprise R\&D investment intensity to 1.2 , which aims to simulate the impact of further increasing R\&D investment and improving innovation levels on the green low-carbon development of coal enterprises. The three scenarios have a positive effect on the green low-carbon development level of coal enterprises. Under Scenario 3, the green low-carbon development level of coal enterprises is the highest, that is, to strengthen the $\mathrm{R} \& \mathrm{D}$ investment of coal enterprises and improve their innovation level, which is the most effective path for the green low-carbon development of coal enterprises. The level of green low-carbon development of coal enterprises takes second place under Scenario 1. The economic benefit of coal enterprises is an important factor that affects this development, and the sustainable profit of coal enterprises is a necessary condition for the sustainable development of coal enterprises. Scenario 2 improves the intensity of environmental regulation. Although it can promote the level of green low-carbon development of coal enterprises, the effect is very small. This is mainly because environmental regulations have not been relaxed in recent years, and the environmental conditions of enterprises are improving. Excessive environmental regulation would increase the costs of enterprises. The development level of green low-carbon coal enterprises is mainly affected by the economic situation. This is also illustrated by the trend of the economic situation and environmental situation in Figure 5.

5.2.3. Scenario Analysis under Mixed Factor Influence. Figure 7 shows the changes in the coupling coordination degree under the original scenario and Scenarios 4 to 6 . It can be seen from Figure 7 that Scenarios 4 to 6 all improve the green low-carbon development level of coal enterprises. From the overall changes in the past 15 years, the effect of Scenario 4 is not good in the late stage; however, on the contrary, the effect of Scenario 6 is more sustainable. This shows that appropriate environmental regulations would be conducive to the green low-carbon development of coal enterprises, but are not the most stable way in the long-term. Development that is innovation driven is the most effective way to promote the sustainable development of enterprises. Compared with the original scenario, Scenarios 4 to 6 have a positive effect, but what combination would be more conducive to the green low-carbon development of coal enterprises is a question. To answer this, we need to further compare the results of single-factor and mixed-factor 


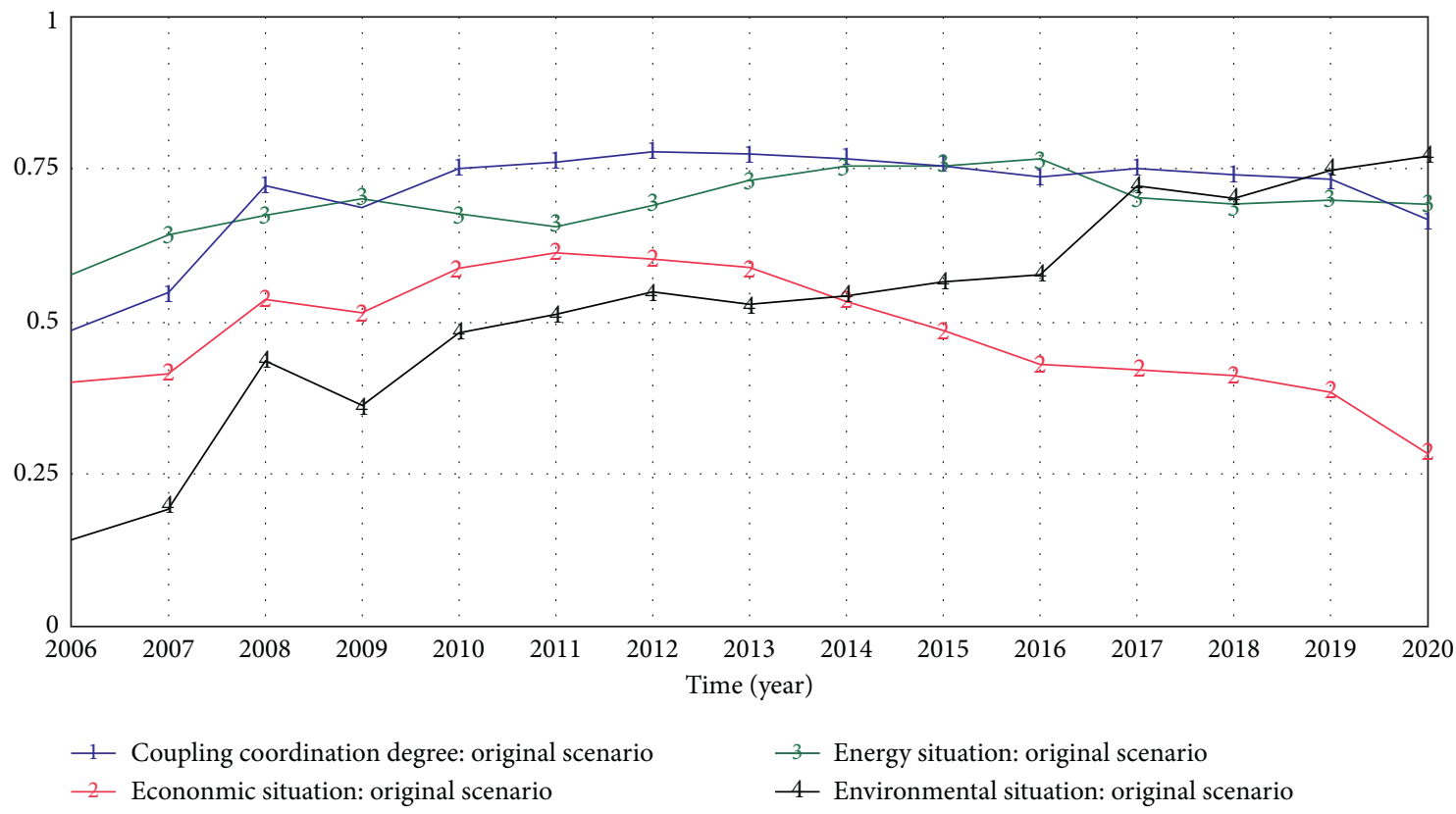

FIGURE 5: Green low-carbon development of coal enterprises under the original scenario.

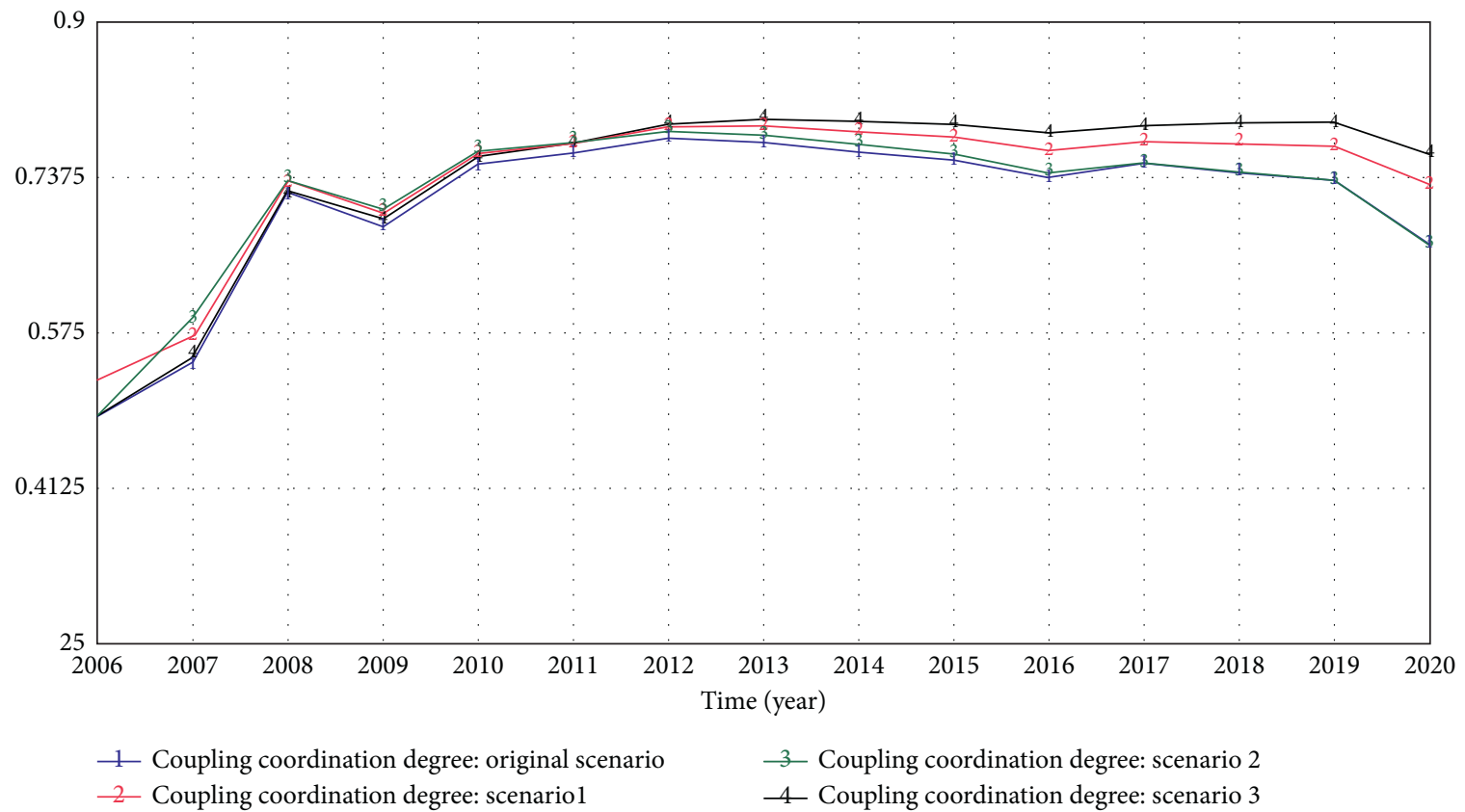

FIGURE 6: Influence of single factor change on the green low-carbon development level of coal enterprises.

impacts. Figure 8 shows the operation results for Scenarios 1 to 6. Comparing Scenario 1 with Scenario 4, the latter enhances environmental regulation intensity based on the former. By comparing the two scenarios, we explore whether strengthening environmental regulations would benefit the green low-carbon development of coal enterprises if the economic benefits of coal enterprises improve. The results we obtained show that Scenario 4 results in a better effect than Scenario 1 before 2015. However, after 2015, strengthening environmental regulations had little effect. Properly strengthening the intensity of environmental regulations would be conducive to the green low-carbon development of coal enterprises. Excessive intensity of environmental regulations cannot produce positive effects. Comparing Scenario 5 with Scenarios 2 and 3, Scenario 5 evidently leads to the greatest improvement in the green low-carbon development level of coal enterprises, followed by Scenario 3 and Scenario 2. Organic combination of appropriate environmental regulation and innovation drive can better promote the green low-carbon development level of coal enterprises. Comparing Scenario 6 with other scenarios, although affected by the bad market environment at 


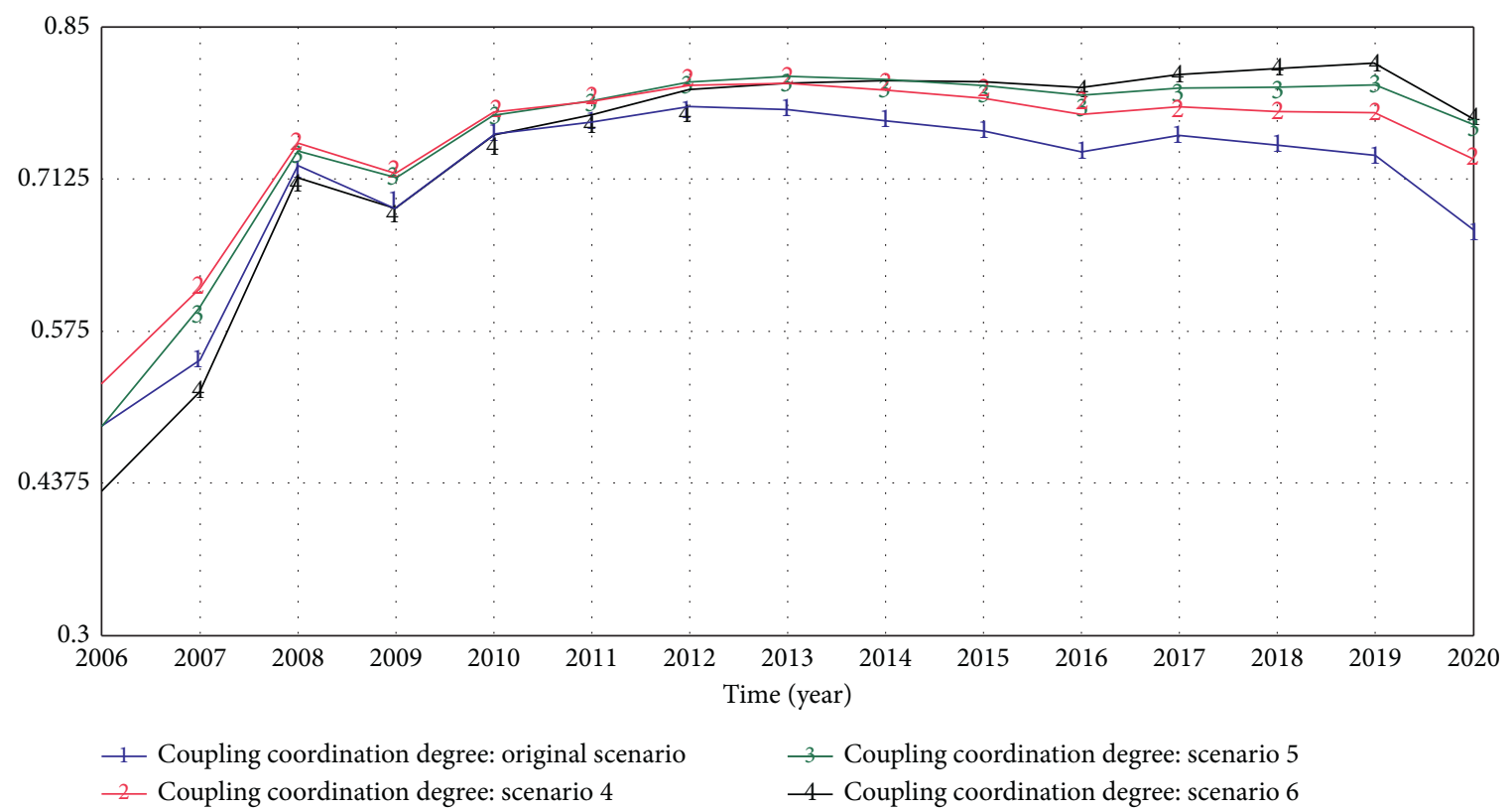

FIGURE 7: Influence of mixed factor change on the green low-carbon development level of coal enterprises.

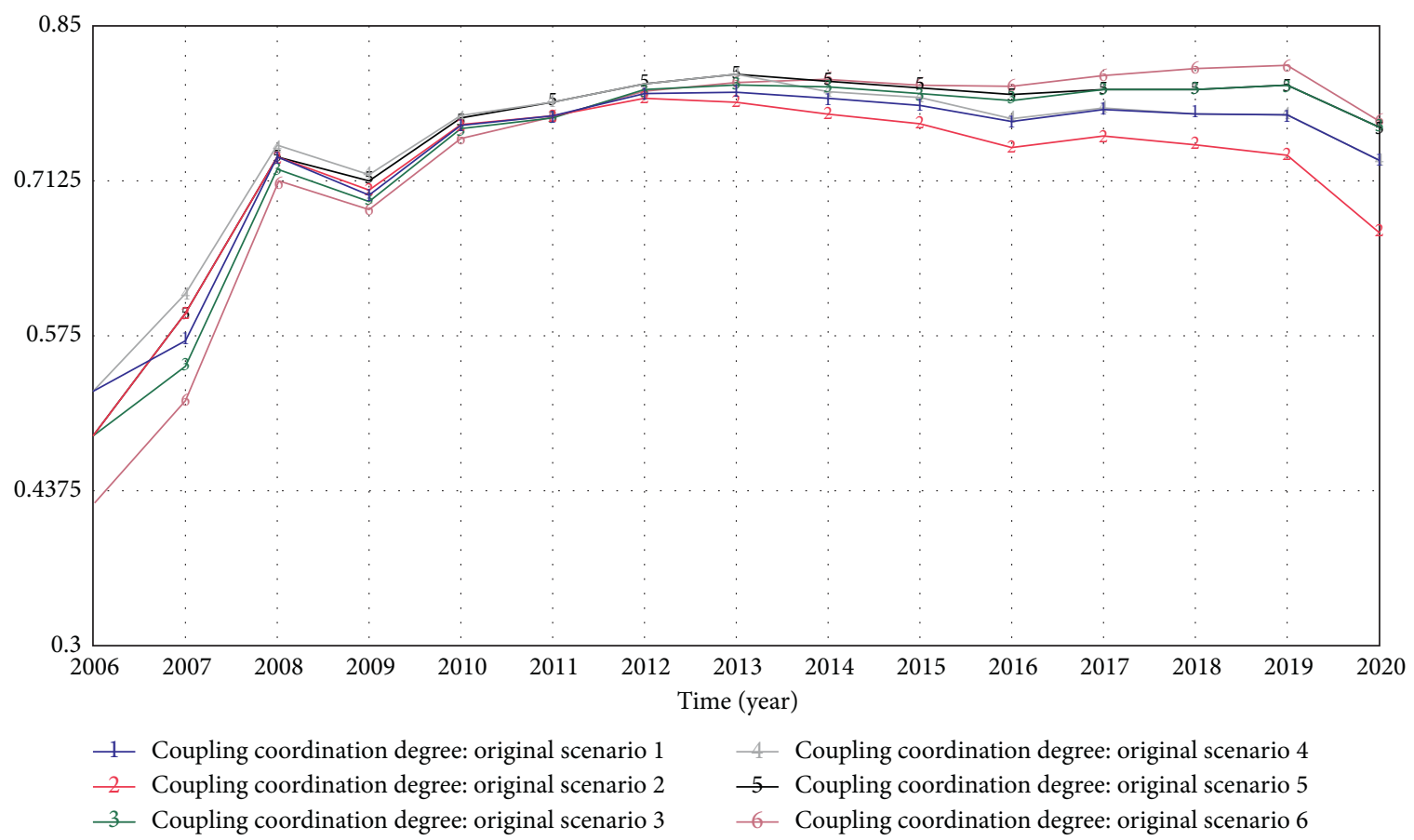

Figure 8: Green low-carbon development level of coal enterprises under Scenarios 1 to 6.

the beginning, the green low-carbon development level of coal enterprises under Scenario 6 had been at the lowest level before 2012; however, its development trend was essentially on the increasing trend. Since 2012, the trend under this scenario gradually surpassed other scenarios, and after 2015, the green low-carbon development level has been higher than the other scenarios, which shows that even when the coal market environment is depressed and the economy of coal enterprises is damaged, coal enterprises can drive the development of enterprises with innovation, and by vigorously improving the level of innovation, the enterprise can reverse the scenario and realize sustainable development.

In summary, the market environment, appropriate government regulation, and enterprises' innovation level have a positive impact on the level of green low-carbon development of enterprises. The effect intensity of the enterprise innovation level is higher than that of market factors and higher than that of government environmental regulation. The organic combination of appropriate government 
environmental regulation and development that is innovation-driven would better promote the green low-carbon development of coal enterprises, which is an effective way for the sustainable development of coal enterprises.

\section{Conclusions and Suggestions}

Based on the self-organization theory, this study clarifies the self-organization evolution logic of green low-carbon development of coal enterprises and proposes that this development is affected by the external market environment, environmental regulations, and the enterprises' internal innovation level. The system simulation model of green lowcarbon development of coal enterprises is constructed using the system dynamics method, which is simulated using the relevant data of the coal industry from 2006 to 2015. This study reveals the influence of the market environment, environmental regulation, and enterprises' innovation level on the green low-carbon development of coal enterprises through a scenario simulation analysis and attempts to put forward applicable suggestions for the green low-carbon development of coal enterprises based on the simulation results. Based on the scenario simulation results regarding system dynamics, the following conclusions and suggestions are drawn.

(1) The coal market environment restricts the level of green low-carbon development of coal enterprises and is still the main challenge faced by coal enterprises.

After experiencing its "golden decade," China's coal market entered a historic turning point in 2013. Affected by the slowdown of economic growth, energy reforms, and impact of imported coal, the demand for coal dropped sharply, a surplus in the supply capacity occurred, the relationship between supply and demand became unbalanced, and coal prices fell, reaching a significantly low level in 2015. A large number of coal enterprises were deeply mired in difficult situations, and the economic benefits of coal enterprises were seriously damaged. In 2016, the State Council issued the "Opinions on Resolving Excess Capacity in the Coal Industry and Realizing the Development Out of Poverty," which combined actively and steadily resolving excess capacity with structural adjustment, transformation, and upgrading, and helped the coal industry reverse the deficit, eliminate difficulties, upgrade, and engage in healthy development. These actions achieved good results. The business landscape is gradually recovering, and the economic benefits of coal enterprises are gradually improving; nevertheless, the landscape has still not fully recovered, which is consistent with the simulation results of the original scenario in this study. At the same time, we found that China's coal enterprises are greatly affected by fluctuations in the coal market. When the coal market declines, the economic benefits of coal enterprises decline or they even lose money. The core competitiveness and sustainable development mechanism needed to counter market turbulence has yet to be formed. Hence, coal enterprises should further explore the mechanism of sustainable development, and the formation of core competitiveness should be the focus of future development.

(2) Appropriate environmental regulations can promote the green low-carbon development of coal enterprises.

The results of our scenario simulation show that appropriate environmental regulations may further improve the environmental conditions of coal enterprises and, subsequently, the level of their green low-carbon development. However, if the economic situation of coal enterprises is poor, excessive environmental regulations may burden enterprises, which would curb their green low-carbon development. However, in the current and foreseeable future, the dominant position and ballast role of coal in China's energy system is not expected to change significantly, and the pressure of ecological environmental protection is expected to increase further. Strengthening environmental regulations is inevitable. Hence, coal enterprises should further explore ways to balance the environment and economy to realize green mining and clean, efficient, and intensive utilization.

(3) Improving the level of innovation is the most effective way for coal enterprises to improve the level of green and low-carbon development.

Innovation has always been the most effective way for enterprises to enhance their core competitiveness. For coal enterprises, green innovation may effectively promote these enterprises' green lowcarbon development. As the results of our scenario simulation show, even if the market environment further deteriorates, coal enterprises can reverse this trend through innovation. Hence, coal enterprises should put green innovation in the core position of green low-carbon development, increase R\&D investment, increase the introduction of talent, improve the level of scientific and technological innovation, improve production efficiency through science and technology, produce high-quality coal, eliminate backward production capacity, develop advanced production capacity, promote the highquality development of coal enterprises, and replace the development mode of high yield and low efficiency with high quality and high efficiency. As information technology has evolved, digital media have become increasingly fragmented and have started to proliferate multiple information channels [22]. Through breakthrough innovation, it will promote the intelligent and information construction of coal mines, form a safe green and efficient intelligent mine technology system, and realize the 
safe and efficient intelligent production of coal. At the same time, through the innovation of system and mechanism, the transformation and upgrading of enterprises should be accelerated, the efficiency of resource allocation improved, and the green lowcarbon sustainable development of coal enterprises promoted.

\section{Data Availability}

The data that support the findings of this study are openly available in China Industrial Statistical Yearbook, China Environmental Statistical Yearbook, China Science and Technology Statistical Yearbook, and China Energy Statistical Yearbook (https://data.cnki.net/Yearbook/).

\section{Conflicts of Interest}

The authors declare that there are no conflicts of interest regarding the publication of this paper.

\section{Acknowledgments}

This research was funded by the National Natural Science Foundation of China (Grant no. 71774105), Soft Science Research Project in Shanxi Province, China (Grant no. 2019041012-1), and Planning Project of Philosophy and Social Sciences in Shanxi Province, China (Grant no. 2020YY093).

\section{References}

[1] World Commission on Environment and Development (WCED), Our Common Future, Oxford University Press, Oxford, UK, 1987.

[2] Y. Chen, S. Liu, H. Wu, X. Zhang, and Q. Zhou, "How can Belt and Road countries contribute to glocal low-carbon development?" Journal of Cleaner Production, vol. 256, Article ID 120717, 2020.

[3] S. Fang and Z. Ding, "Research on green and low carbon development from the perspective of ecological harmony," China Population, Resources and Environment, vol. 11, pp. 58-61, 2011.

[4] J. Chen and H. Zhou, "Empirical analysis on the coupling relationship between human capital and economic growth in China's provinces," The Journal of Quantitative \& Technical Economics, vol. 30, pp. 3-19, 2013.

[5] M. Pedercini, "Potential contribution of existing computerbased models to comparative assessment of development options," Working Papers in System Dynamics, University of Bergen, Bergen, Norway, 2003.

[6] B. Fernando, "Self-organizing market structures, system dynamics, and urn theory," Complexity, vol. 18, pp. 28-40, 2013.

[7] M. Luo, "On the transformation of organizational theory paradigm," Foreign Economics \& Management, vol. 30, pp. 18-22, 2008.

[8] I. Prigogine, Exploring Complexity, Sichuan Education Press, Chengdu, China, 3rd edition, 2010.

[9] H. Haken and J. Portugali, "Information and selforganization,” Entropy, vol. 19, pp. 1-6, 2017.
[10] A. Shahri, M. Hosseini, K. Phalp, J. Taylor, and R. Ali, "How to engineer gamification," Journal of Organizational and End User Computing, vol. 31, no. 1, pp. 39-60, 2019.

[11] M. Luo and S. Zhou, "On the complexity of organization," Foreign Economics \& Management, vol. 33, pp. 26-33, 2011.

[12] X.-Y. Duan, H.-J. Chou, and S.-R. Cheng, "Recognition and empirical research on key influencing factors of low carbon development for logistics company," Discrete Dynamics in Nature and Society, vol. 2015, Article ID 851492, 9 pages, 2015.

[13] M. Pei, B. Zhang, G. Sun, and B. Qi, "Research on business incubation process based on system dynamics model," Forum on Science and Technology in China, vol. 8, pp. 64-70, 2016.

[14] Y. Zhang, C. Yuan, and J. Wu, "Research on the construction and evolution of China's logistics industry innovation ecosystem under the background of 5G," Scientific Management Research, vol. 38, pp. 62-70, 2020.

[15] N. Han, "Carbon emission reduction path and simulation control based on supply side structural reform," China Population, Resources and Environment, vol. 28, pp. 47-55, 2018.

[16] J. Tian and J. Xu, "Research on driving factors of business model innovation of platform enterprises," Studies in Science of Science, vol. 38, pp. 949-960, 2020.

[17] Y. Liu, W. Wu, and B. Yu, "The influence of technology management capability on the behavior of breakthrough technology innovation," Studies in Science of Science, vol. 38, pp. 925-935, 2020.

[18] X. Zhang and W. Wang, "Simulation of policy effects of different types of environmental regulations on China's industrial green development," Science-Technology and Management, vol. 20, pp. 34-44, 2018.

[19] Z. Gong and M. Li, "Simulation of creative performance evolution mechanism based on system dynamics," Statistics \& Decision, vol. 11, pp. 158-161, 2020.

[20] S. Yang, "Multi scenario simulation and empirical research on regional green development based on system dynamics," Systems Engineering, vol. 35, pp. 76-84, 2017.

[21] C. Allen, G. Metternicht, and T. Wiedmann, "National pathways to the sustainable development goals (SDGs): a comparative review of scenario modelling tools," Environmental Science \& Policy, vol. 66, pp. 199-207, 2016.

[22] G. Khatwani and P. R. Srivastava, "Impact of information technology on information search channel selection for consumers," Journal of Organizational and End User Computing, vol. 30, no. 3, pp. 63-80, 2018. 